\title{
Alcohol Use and Cognition at Mid-Life: The Importance of Adjusting for Baseline Cognitive Ability and Educational Attainment
}

\author{
Dean Krahn, Jeremy Freese, Robert Hauser, Kristen Barry, and Brian Goodman
}

\begin{abstract}
Background: The nature of the relationship between cognition and alcohol consumption remains controversial. Studies have reported negative, positive, and nonsignificant effects of alcohol consumption on cognition. Problematic throughout the literature is that baseline cognitive ability has not been adequately controlled in previous studies, and even educational attainment is only sometimes controlled. Because such variables may be associated with both alcohol intake and later-life cognition, we hypothesize that the observed relationship between alcohol intake and cognition may change when these variables or other conditions in early life have been controlled.

Methods: We examined the relationship of alcohol intake and cognition at age 53 using the Wisconsin Longitudinal Study, which has followed Wisconsin high school graduates from 1957 to 1992. Our measures include cognitive ability test scores from the freshman and junior years of high school, educational attainment, an abstract reasoning test score at age 53, alcohol intake at age 53, and other measures.

Results: When no controls were used, both men and women with low levels of alcohol consumption at 53 (i.e., 0-1 drink per day) had better scores on the abstract reasoning subtest of the Wechsler Adult Intelligence Scale (WAIS-R) at age 53 than subjects who never drank or currently did not drink. However, after adjusting for adolescent-measured cognitive ability and educational attainment, men with low levels of consumption no longer had higher abstract reasoning scores than nondrinking men, but they still did have higher abstract reasoning scores than men who drank more than one drink per day. For women, adjusting for cognitive ability and educational attainment eliminated all significant effects of alcohol on cognition, and reversed the nonsignificant result that women with higher consumption had the highest cognition scores. These results demonstrate the importance of adjusting for baseline cognitive ability when attempting to study the effect of long-term alcohol use patterns on cognition, and that educational attainment cannot be considered a valid substitute for baseline cognition scores.

Conclusions: Much of the apparent benefit of moderate alcohol intake on cognition in our society may well be explained by differential rates of alcohol consumption among subjects with differing baseline cognitive ability scores. Neither is there evidence that moderate alcohol intake reduces cognitive functioning.

Key Words: Cognition, Alcohol, IQ, Education, Consumption.
\end{abstract}

$\mathbf{T}_{t}$ HE RELATIONSHIP BETWEEN alcohol consumption and cognitive function remains unclear. Probably because of the acute effects of alcohol during intoxication,

William S. Middleton Memorial Veterans Hospital (D.K., B.G.); University of Wisconsin School of Medicine (D.K.); University of Wisconsin Department of Sociology (J.F., R.H.); Center for Demography of Health and Aging, University of Wisconsin (J.F., R.H.), Madison WI; University of Michigan Department of Psychiatry, Ann Arbor MI (K.B.).

Received for publication November 22, 2002; accepted April 7, 2003.

This research was conducted at the William S. Middleton Memorial Veterans Hospital in Madison, WI, and at the Center for Demography of Health and Aging, University of Wisconsin-Madison. It was supported by the Veterans Administration Merit Review Program and by the National Institute on Aging (R01-AG09775-10 and P01-AG21079-01). The opinions expressed herein are those of the authors.

Reprint requests: Dean Krahn, MD, MS, Wm. S. Middleton Memorial Veterans Hospital, 2500 Overlook Terrace, Madison WI 53705; Fax: 608280-7203; E-mail: dean.krahn@med.va.gov

Copyright (C) 2003 by the Research Society on Alcoholism.

DOI: 10.1097/01.ALC.0000078060.18662.C1 its neurotoxicity, and its association with dementia, many clinicians believe that alcohol is deleterious for cognition (Victor et al., 1989). Studies in nonclinical samples most often show no significant relationship between alcohol intake and cognition (Carey and Maisto, 1987; Dent et al., 1997; Hannon et al., 1985; Jones-Saumty and Zeiner, 1985). However, over the last 10 years, a number of studies have reported that middle-aged and older subjects who drank low to moderate amounts of alcohol scored higher on a variety of cognitive measures than did abstainers (Christian et al., 1995; Goodwin et al., 1987; Hebert et al., 1993; Hendrie et al., 1996; Launer et al., 1996). Some report a Uor J-shaped, curvilinear relationship between the amount of alcohol consumed and cognitive function such that lowmoderate drinkers exceed both abstainers and heavy drinkers on cognitive measures (Christian et al., 1995; Goodwin et al., 1987; Hebert et al., 1993; Hendrie et al., 1996; Launer et al., 1996). For example, Galanis et al. (2000), reported that elderly (ages 71-93) Japanese-American men who 
drank up to two drinks per day had significantly less risk of a poor cognitive outcome than did subjects who were either nondrinkers or had more than two drinks per day. In the Framingham Heart Study (Elias et al., 1999), cognitive performance was better in subjects who drank in what the investigators termed a moderate manner than in abstainers. This study showed a more consistently beneficial effect of alcohol intake in cognition for women than men. Also, this study suggested best cognitive performances at the seemingly relatively high level of 2-4 drinks per day in women and 4-8 drinks per day in men. Orgogozo et al. (1997) reported that moderate wine drinkers in a French sample had a markedly reduced risk for Alzheimer's disease and dementia compared to nondrinkers. While some studies continue to show no benefit for cognition due to alcohol consumption (Edelstein et al., 1998; Elwood et al., 1999; Graves et al., 1991) some speculate that the antioxidant effects of red wine and/or the positive effects of alcohol on atherosclerotic cardiovascular disease could mediate alcohol's presumed benefits (DeLorimier and Tompkins, 2000).

In the absence of a randomized, controlled study of the effects of alcohol on cognition, it is unlikely that any naturalistic, epidemiologic study will completely resolve the question of whether moderate alcohol intake helps cognition. But, conclusions about the effects of alcohol on cognition would be strengthened if one could adjust current cognition scores using a measure of cognition that antedated the period of significant alcohol intake. The Wisconsin Longitudinal Study data contains cognitive ability measures from age 17 (as well as often age 15) for subjects who also reported on alcohol intake and performed cognitive tests at age 53. The availability of this baseline measure allows the suggested adjustment of the findings regarding cognition and alcohol intake at 53. If subjects with significantly differing baseline levels of cognitive ability drank significantly different amounts of alcohol, then the apparent "benefit" of alcohol consumption might actually be due to the confounding effects of the relationship of alcohol intake and cognition. We tested this hypothesis as well as the hypothesis that adjusting for education level might have a similar effect on the relationship between alcohol intake and cognition.

\section{METHODS}

Data were obtained from the Wisconsin Longitudinal Study (Hauser et al., 1977; Hauser et al., 1993). The Wisconsin Longitudinal Study (WLS) is a long-term study of 4,994 men and 5,323 women (total $=10,317$ ) who graduated from Wisconsin high schools in 1957 (Sewell et al., 2003). WLS participants are a one-third, simple random sample of all Wisconsin high school graduates in the class of 1957. The WLS cohort is comprised almost exclusively of white, non-Hispanic Americans (of mainly German, English, Irish, Scandinavian, Polish, or Czech ancestry). The WLS includes survey data collected from the original respondents or their parents in 1957 (10,317 in-person surveys), 1964 (8,923 mail surveys), 1975 (9,138 telephone surveys), and 1992 (8,493 telephone surveys). There had been 576 confirmed deaths by 1992, leaving a potential sample of 9,741, of whom fewer than 300 were not located. Alcohol use data were obtained in 1992 from a random $80 \%$ subsample of WLS participants in the course of a one-hour telephone interview.

The WLS provides a comprehensive record of social background, youthful aspirations, schooling, military service, family formation, labor market experiences, and social participation of the original respondents. The survey data from earlier years have been augmented by archival information on mental ability test scores and measures of school performance, among other things. In the follow-up surveys, the content has also been extended to obtain detailed information in a wide range of areas, including alcohol use. Documentation, publication lists, and modular-public-use data files from the WLS are available from the University of Wisconsin-Madison Data and Program Library Service, (http://dpls.dacc.wisc.edu/WLS/). Additional source materials about the WLS are available from The Wisconsin Longitudinal Study, Center for Demography of Health and Aging, The University of WisconsinMadison, 1180 Observatory Drive, Madison, WI 53706 (e-mail: wls@ ssc.wisc.edu).

The measures of interest for this study were obtained in the following manner.

\section{High School Cognitive Ability Scores}

Most of the WLS respondents completed the Henson-Nelson test of mental ability during their freshman and junior years of high school. These scores were subsequently obtained from the files of the Wisconsin State Testing Service. We used age-normed averages of the freshman and junior scores when available (approximately $70 \%$ of the sample), and otherwise used the age-normed junior year score.

\section{Educational Attainment}

In 1975 or-in a few cases-1992, WLS respondents reported their highest level of completed schooling or highest degree earned, and this information was expressed in equivalent years of regular schooling, according to standards used by the U.S. Bureau of the Census.

\section{Current Cognition Scores}

In 1992-1993, when the WLS participants were approximately 53 years old, they were administered an 8-item, abbreviated version of the similarities subtest of the Wechsler Adult Intelligence Scale (WAIS-R) (Wechsler, 1987). The similarities subtest asks subjects how two things are alike (e.g., an orange and a banana), and scores of 0,1 , or 2 points are given based on both the correctness and abstractness of the response. The similarities subtest is thought to be primarily a measure of "crystallized intelligence." This is an obviously limited measure of general cognitive functioning. In the WAIS-R, the reported correlation between the full 17 -item similarities test score and the overall cognitive ability score is 0.82 ; the correlation between the subtest and overall score is unknown but is presumably lower. The measure of cognitive functioning at age 53 is thus obviously and seriously limited, although, as our results below indicate, it is far from uninformative. The forthcoming 2003-2004 round of the WLS will include more extensive measures of cognitive functioning that will allow a more elaborate examination of the hypotheses considered here.

\section{Current Alcohol Use Questions}

The 1992-3 WLS alcohol use questions address current consumption of alcoholic beverages (i.e., number of days during the last month had an alcoholic drink, average number of drinks had on those days, and number of drinks in the last month). Note that these questions do not address past alcohol use behavior.

\section{Other Measures}

Supplementary analyses explored the possible consequences of also adjusting for characteristics of respondent's family background (e.g., their parents' socioeconomic status) as well as the respondent's educational and occupational aspirations in high school. Unlike baseline cognitive ability 
Table 1. WLS Males: Ordered Probit Coefficients for Regression of Similarities Subtest Score on Alcohol Use, Adolescent-Measured Cognitive Ability, and Educational Attainment

\begin{tabular}{|c|c|c|c|c|}
\hline & Model 1 & Model 2 & Model 3 & Model 4 \\
\hline \multicolumn{5}{|c|}{ Drinking behavior (relative to 1-29 drinks/month) } \\
\hline \multirow[t]{2}{*}{ Never drank } & $-0.296^{\star \star}$ & $-0.194^{*}$ & $-0.204^{\star}$ & -0.161 \\
\hline & $(0.094)$ & $(0.094)$ & $(0.094)$ & $(0.095)$ \\
\hline \multirow[t]{2}{*}{ No drinks in last month } & $-0.112^{\star}$ & -0.023 & -0.024 & 0.011 \\
\hline & $(0.047)$ & $(0.047)$ & $(0.047)$ & $(0.048)$ \\
\hline \multirow[t]{2}{*}{$>30$ drinks in last month } & $-0.107^{\star}$ & $-0.166^{\star \star}$ & -0.076 & $-0.133^{\star *}$ \\
\hline & $(0.045)$ & $(0.046)$ & $(0.045)$ & $(0.046)$ \\
\hline \multicolumn{5}{|l|}{ Baseline controls } \\
\hline \multirow[t]{2}{*}{ Adolescent-measured cognitive ability } & & $0.034^{\star *}$ & & $0.025^{\star *}$ \\
\hline & & $(0.001)$ & & $(0.001)$ \\
\hline \multirow[t]{2}{*}{ Educational attainment (in years) } & & & $0.174^{\star \star}$ & $0.110^{\text {** }}$ \\
\hline & & & $(0.008)$ & $(0.009)$ \\
\hline
\end{tabular}

$N=$ 2983. Standard errors in parentheses. ${ }^{\star} p<0.05,{ }^{\star \star} p<0.01$.

and educational attainment, however, including these measures in our regression models had no appreciable effect on the results.

\section{RESULTS}

There were 2,984 male WLS respondents and 3,453 female respondents at age 53 who had IQ measures from their high school years available and who responded to the alcohol and cognition questions in 1992. Those respondents represent an $83 \%$ participation rate of the living, original subjects who were part of the random $80 \%$ subsample who received questions on alcohol use. Analyses of basic sociodemographic characteristics do not suggest substantively consequential differences between participants and nonparticipants.

Because tests indicated that the dependent variable was better treated as an ordinal measure than an interval one, we used ordered probit models to estimate the relationship between mid-life cognitive ability and alcohol consumption with and without controlling for the potential confounding influences of early adult cognitive ability and educational attainment (Long and Freese, 2001). The ordered probit model presumes that the observed categorical outcome can be interpreted as the ordered outcomes of a latent continuous variable (in this case, abstract reasoning ability) whose error variance is scaled to equal 1 . Coefficients from the ordered probit model correspond then to the changes in this latent variable that are associated with unit increases in the explanatory variables. Regarding alcohol use, respondents have been divided into four categories: those who reported having never drank $(4.1 \%$ of men, $6.7 \%$ of women), those who reported having not drank in the last month (22.0\% of men, $27.5 \%$ of women), those who reported drinking between 1 and 29 drinks in the past month (49.0\% of men, $57.2 \%$ of women), and those who drank more than this $(24.8 \%$ of men, $8.6 \%$ of women). The tables present differences in the latent outcome relative to the reference category of those drinking 1-29 drinks in the past month. Because preliminary analyses indicated sex differences in the relationship between alcohol use and midlife cognition, all data analyses presented below were conducted separately for men and women.
Table 1 presents the results of our analyses for men. We present first the results of a "naïve" cross-sectional model in which neither baseline cognitive ability nor educational attainment are controlled (Model 1), and then in subsequent models we show the consequences of adjusting for cognitive ability (Model 2), educational attainment (Model 3 ), and both (Model 4). From the naïve model, we can see that males who consume low amounts of alcohol have significantly higher scores on the abstract reasoning task than those who drank either more or less. However, regarding any proposed interpretation of this as the result of alcohol consumption, we can see immediately from Model 2 that once the earlier measure of cognitive ability is introduced into the model, the significant difference between those who did not drink in the past month and those who drank 1-29 drinks disappears. Meanwhile, the difference between those with low levels of alcohol consumption and those who drank more than 30 drinks in the last month actually increases with the addition of the adolescent cognitive ability measure, suggesting the possibility that failing to control for baseline cognitive ability might actually suppress part of a negative relationship between higher levels of alcohol consumption and cognitive change. In Model 3, we can see that this potential suppression is not something we would have discovered had we simply taken educational attainment as a proxy for baseline cognitive ability, as is commonly done. In the full model, we see no significant difference between nondrinking and low levels of alcohol consumption, but we continue to observe lower abstract reasoning scores among those with higher levels of alcohol consumption when cognitive ability and educational attainment are controlled.

Table 2 presents findings for women. Here, from the naïve model, we see that those who have never drank have significantly lower abstract reasoning scores at age 53 than those with low levels of alcohol consumption, and we can also see that those with higher levels of consumption have nonsignificantly higher levels of cognition. In Model 2, however, we see that adjusting for cognitive ability again reduces the relationship between never drinking and low levels of drinking to nonsignificance, and it also changes the 
Table 2. WLS Females: Ordered Probit Coefficients for Regression of Similarities Subtest Score on Alcohol Use, Adolescent-Measured Cognitive Ability, and Educational Attainment

\begin{tabular}{|c|c|c|c|c|}
\hline & Model 1 & Model 2 & Model 3 & Model 4 \\
\hline \multicolumn{5}{|c|}{ Drinking behavior (relative to 1-29 drinks/month) } \\
\hline Never drank & $\begin{array}{c}-0.311^{\star *} \\
(0.070)\end{array}$ & $\begin{array}{r}-0.124 \\
(0.070)\end{array}$ & $\begin{array}{c}-0.277^{\star \star} \\
(0.070)\end{array}$ & $\begin{array}{r}-0.135 \\
(0.070)\end{array}$ \\
\hline No drinks in last month & $\begin{array}{c}-0.032 \\
(0.040)\end{array}$ & $\begin{array}{c}0.029 \\
(0.040)\end{array}$ & $\begin{array}{r}-0.011 \\
(0.040)\end{array}$ & $\begin{array}{c}0.032 \\
(0.040)\end{array}$ \\
\hline$>30$ drinks in last month & $\begin{array}{c}0.052 \\
(0.063)\end{array}$ & $\begin{array}{r}-0.042 \\
(0.063)\end{array}$ & $\begin{array}{c}0.046 \\
(0.063)\end{array}$ & $\begin{array}{r}-0.029 \\
(0.063)\end{array}$ \\
\hline \multicolumn{5}{|l|}{ Baseline controls } \\
\hline Adolescent-measured cognitive ability & & $\begin{array}{l}0.036^{\star *} \\
(0.001)\end{array}$ & & $\begin{array}{l}0.030 \text { ** } \\
(0.001)\end{array}$ \\
\hline Educational attainment (in years) & & & $\begin{array}{l}0.199^{\star \star} \\
(0.009)\end{array}$ & $\begin{array}{c}0.128^{\star \star} \\
(0.010)\end{array}$ \\
\hline
\end{tabular}

$\mathrm{N}=$ 3453. Standard errors in parentheses. ${ }^{\star} p<0.05,{ }^{\star *} p<0.01$.

direction of the nonsignificant association between midlife cognition and relatively high levels of consumption. Once again, Model 3 shows that even though educational attainment is commonly regarded as an adequate proxy for baseline cognitive ability, neither of these changes in the effects of alcohol use is observed when only educational attainment is controlled. In the full model, we observe no significant differences between any level of alcohol use (as compared to any other level) and cognition.

\section{DISCUSSION}

A simple cross-sectional assessment of the relationship between cognition as measured by the WAIS similarities subtest at 53 years old and alcohol intake would appear to provide support for the hypothesis that mild to moderate alcohol intake promotes better cognitive functioning. In men, this relationship between alcohol intake and midlife cognition is found in our cross-sectional analysis, while in women higher alcohol intake is associated with even better cognitive functioning.

However, in our sample, we find that when one adjusts for cognitive ability as measured at ages 15 and 17 (i.e., presumably prior to the onset of significant alcoholinduced neurotoxicity), much of the apparent positive relationship between alcohol consumption and midlife cognition disappears. Moreover, what remains significant is the suggestion of a possible negative relationship between higher levels of consumption and lower levels of cognition in men. For women, the adjustment for cognitive ability eliminates all significant relationships. The reason for these changes is that higher adolescent-measured cognitive ability is associated with relatively higher levels of later alcohol use, and this relationship can lead to misleading conclusions about the direction of causality when looking at purely cross-sectional data.

It is rare for samples whose members are as old as WLS participants to have a baseline cognitive ability measure. Consequently, retrospectively available proxies for baseline cognitive ability are desirable, and in this regard one might consider educational attainment to be the best candidate. While this may indeed be so, what our analyses show is that one should not identify a statistical control for educational attainment with a genuine control for baseline cognition, as the consequences of including these variables independently can be quite divergent. Put simply, adjusting for educational attainment is not the same as adjusting for baseline cognitive ability, even though it would make the analysis of the effects of long-term alcohol use on cognition much simpler if this were the case.

Having said this, it is important to acknowledge several limitations of this study. Central among these are the use of the single WAIS subscale as the outcome, the potential desirability of studying respondents older than age 53 , the lack of information about consumption prior to age 53, the use of different cognitive measures at $15-17$ and 53 years of age, and the homogeneity of the sample in terms of ethnicity, age, and state of origin. ${ }^{1}$ Together, these are sufficient to urge caution against over-interpreting these results, although the presence of significant results and changes from nonsignificance to significance (and vice versa) suggests that associations between the outcome and other measures may be sufficiently durable that useful results can be produced even when cognition is measured in a quite limited fashion.

We have not been able to demonstrate a beneficial effect of low or moderate drinking at age 53 when prior cognitive status is taken into account. While significant atherosclerotic vascular disease is present by age 53, one might argue that, if the posited beneficial effects of low levels of alcohol intake are mediated by effects on atherosclerosis, then these benefits should become more obvious with advancing

\footnotetext{
${ }^{1}$ Analyses were also conducted using the WLS companion sample that is based on a randomly selected sibling of many respondents (interviews in 1993-1994). While sample sizes here were smaller and controls for age needed to be included in the models, the results were overall consistent with the findings from the graduate sample. Apparent effects of alcohol on cognition, when present, were eliminated when controls for adolescent cognitive ability and educational attainment were added to the model, although these estimates were not always reduced to nonsignificance when only one of these two controls was included. The only exception was that female younger siblings who never drank had significantly lower WAIS-R scores than their counterparts who reported $1-29$ drinks/month $(\mathrm{p}=0.01)$. These analyses are available upon request.
} 
age. As we have only the age 53 years time point at which alcohol intake and cognition were both measured, these data cannot inform us about this possibility. However, planned measures of alcohol intake and cognition at ages $64-65$ and, potentially, at more advanced ages will allow us to test the hypothesis that low levels of alcohol intake will be beneficial at older ages.

In conclusion, those who are interested in the long-term consequences of alcohol usage are resigned to the impossibility of a randomized, clinical trial of different dosages of alcohol over a long period of human adulthood. Consequently, researchers are forced to rely on observational studies of alcohol use to make judgments about risks and benefits of alcohol use. Toward this end, the value of longitudinal studies should not be underestimated. Our study indicates that the availability of a measure of adolescent cognitive ability substantially changes one's interpretation of the consequences of alcohol use for cognition at age 53. The potential presence of unobserved confounding variables always tempers judgments based on correlations in naturalistic studies, and our study suggests that controlling for baseline cognitive ability is vitally important in the present case in a way that is not adequately captured by measures of education that are much more easily obtained.

\section{REFERENCES}

Carey KB, Maisto SA (1987) Effect of a change in drinking pattern on the cognitive function of female social drinkers. J Stud Alcohol 48:236-242.

Christian JC, Reed T, Carmelli D, Page WF, Norton JA Jr, Breitner JC (1995) Self-reported alcohol intake and cognition in aging twins. J Stud Alcohol 56:414-416.

DeLorimier AA, Tompkins RK (2000) Alcohol, wine, and health. Am J Surg 180:357-361.

Dent OF, Sulway MR, Broe GA, Creasey H, Kos SC, Jorm AF, Tennant C, Fairley MJ (1997) Alcohol consumption and cognitive performance in a random sample of Australian soldiers who served in the Second World War. BMJ 314:1655-1657.

Edelstein S, Krist-Silverstein D, Barret-Connor E (1998) Prospective association of smoking and alcohol use with cognitive function in an elderly cohort. J Women's Health 7:1271-1281.

Elias PK, Elias MF, D'Agostino RB, Silbershatz H, Wolf PA (1999) Alcohol consumption and cognitive performance in the Framingham Heart Study. Am J Epidemiol 150:580-589.

Elwood PC, Gallacher JE, Hopkinson CA, Pickering J, Rabbitt P, Stollery B, Brayne C, Huppert FA, Bayer A (1999) Smoking, drinking, and other life style factors and cognitive function in men in the Caerphilly cohort. Epidemiol Community Health 53:9-14.

Galanis DJ, Joseph C, Masaki KH, Petrovitch H, Ross GW, White L (2000) A longitudinal study of drinking and cognitive performance in elderly Japanese American men: the Honolulu-Asia aging study. Am J Public Health 90:1254-1259.

Goodwin JS, Sanchez CJ, Thomas P, Hunt C, Garry PJ, Goodwin JM (1987) Alcohol intake in a healthy elderly population. Am J Public Health 77:173-177.

Graves AB, van Duijn CM, Chandra V, Fratiglioni L, Heyman A, Jorm AF, Kokmen E, Kondo K, Mortimer JA, Rocca WA, et al (1991) Alcohol and tobacco consumption as risk factors for Alzheimer's disease: a collaborative re-analysis of case-control studies. Int J Epidemiol 20(suppl 2):S48-57.

Hannon R, Butler CP, Day CL, Khan SA, Quitoriano LA, Butler AM, Meredith LA (1985) Alcohol use and cognitive functioning in men and women college students, in Galanater M (ed). Recent Developments in Alcoholism. Vol 1. pp 241-252. Plenum Press, New York.

Hauser, RM, Sewell WH. [principal investigator(s)] (1977) Wisconsin longitudinal study (WLS) [graduates and siblings]: 1957-1977. [machinereadable data file]/Madison, WI: University of Wisconsin-Madison, Data and Program Library Service. [distributor]; http://dpls.dacc.wisc.edu/WLS/ Other_html/documentation.htm

Hauser RM, Sewell WH, Hauser TS, Logan JA, Ryff C, Caspi A, MacDonald MM. [principal investigators(s)] (1993) Wisconsin Longitudinal Study (WLS) [graduates]: 1992/93. [machine-readable data file]/Madison, WI: University of Wisconsin-Madison, Data and Program Library Service. [distributor]; http://dpls.dacc.wisc.edu/WLS/Other_html/documentation.htm

Hebert LE, Scherr PA, Beckett LA, Albert MS, Rosner B, Taylor JO, Evans DA (1993) Relation of smoking and low-to-moderate alcohol consumption to change in cognitive function: a longitudinal study in a defined community of older persons. Am J Epidemiol 137:881-891.

Hendrie HC, Gao S, Hall KS, Hui SL, Unverzagt FW (1996) The relationship between alcohol consumption, cognitive performance, and daily functioning in an urban sample of older Black Americans. J Am Geriatr Soc 44:1158-1164.

Jones-Saumty DJ, Zeiner AR (1985) Psychological correlates of drinking behavior in social drinker college students. Alcohol Clin Exp Res 9:158-163.

Launer LJ, Feskens EJ, Kalmijn S, Kromhout D (1996) Smoking, drinking, and thinking. The Zutphen Elderly Study Am J Epidemiol 143: 219-227.

Long, JS, Freese J (2001) Regression models for categorical dependent variables using Stata. Stata Press, College Station, TX.

Orgogozo JM, Dartigues JF, Lafont S, Letenneur L, Commenges D, Salamon R, Renaud S, Breteler MBJM (1997) Wine consumption and dementia in the elderly: a prospective community study in the Bordeaux area. Rev Neurol 153:185-192.

Sewell WH, Hauser RM, Springer KW, Hauser TS (2003) As We Age: The Wisconsin Longitudinal Study, 1957-2001, in Research in Social Stratification and Mobility (Leicht K ed). JAI Press, Greenwich, CT.

Victor M, Adams RC, Collins GH (1989) The Wernicke-Korsakoff Syndrome and related neurological disorders due to alcoholism and malnutrition. 2nd ed. F.A. Davis, Philadelphia.

Wechsler D (1987) Wechsler Adult Intelligence Scale-Revised. The Psychological Corporation, New York. 